\title{
Economic aspects of ensuring the capacity adequacy of electric power systems
}

\author{
Nikolay Belyaev ${ }^{1 *}$, Andrey Egorov ${ }^{1}$, Nikolay Korovkin ${ }^{2}$ and Vladimir Chudny ${ }^{2}$ \\ ${ }^{1}$ Russian Energy Agency Ministry of Energy of the Russian Federation, Russia \\ ${ }^{2}$ Peter the Great St.Petersburg Polytechnic University, Russia
}

\begin{abstract}
The present report deals with economic issues of selecting means ensuring the capacity adequacy of electric power systems. Cost analysis of various engineering measures ensuring the capacity adequacy has been performed, they are as follows: construction of margin generating capacities, erection of new power transmission lines or increase of transmission capacity of existing power lines. The cost-based analysis has been conducted following investment programs and regulatory acts in place. Recommendations on developing computational models of power systems have been given based on the results obtained in order to assess the capacity adequacy indices with account made for the cost of various engineering measures to be taken for their improvement.
\end{abstract}

\section{Introduction}

The capacity adequacy (CA) studies represent as traditional as ever a highly topical problem in terms of planning the electric power system (EPS) development to which an interest is expressed not only by scientific community or organizations operating in the industry and being in charge for EPS operation and development, but by consumers of electricity and capacity markets as a whole. This is due, first of all, to the problem of generating capacity availability, as the capacity margin technologically required to meet the consumers' need in reliable power supply to be paid on capacity market may be well-grounded only by calculations of capacity adequacy indices (CAI) [1-3].

Issues connected with the analysis of capacity adequacy have been given a great attention in national and foreign literature. Except for various models and techniques of CAI evaluation, a range of specialized software packages has been developed as of today both in Russia and abroad to perform relevant calculations (GE MARS, GridView, Orion, Yantari etc.) [4-6]. However, some issues related to the evaluation of power grid CAI do not have a unique solution and in view of this present an area of special scientific interest. These issues include the simulation of transmission line and accounting for capacity transmission constraints when evaluating CAI of meshed systems with weak tie lines.

The paper examines economic aspects of transmission line simulation when analyzing the EPS capacity adequacy. First, common issues of EPS simulation have been studied to evaluate CAI and to optimize the capacity margin, then a feasibility study of taking into account various power transmission constraints has been carried out on the basis of comparing the cost of margin capacity and that one of various engineering solutions aimed at ensuring the transmission capacity increase in power grid.

\section{EPS transport models}

In prevailing practice of CAI calculations the structure of EPS transmission network is presented as a transport (multi-node) model which makes an aggregate of reliability zones (concentrated nodes) and tie-lines between them of given transmission capacity [3,5]. Each reliability zone is an aggregate of nodes of basic grid in EPS where there are no transmission constraints or where they do not affect a mutual reserve capability of given nodes under eventual capacity settlement within the system. Ties between reliability zones are determined based on power grid topology, they may represent one or several overhead electric lines (OHL) whose power flow is limited by some criteria or others. When evaluating CAI, their values are defined for each reliability zone, thus the correctness of multi-zone model formation defines directly the correctness of results obtained on its basis.

The main task of EPS multi-zone model formation is to define transmission constraints between zones. The formation of reliability zones and determination of tieline transmission capabilities are to be performed with due account made for these constraints. Saying that we know that each power grid component has its limit transmission capability, which is specified by one or several factors. However, not each of these limitations may affect the level of CA, that is why it makes no sense to take into account all transmission constraints identified for EPS, as calculations become very complicated, but they do not affect their results. In this 
context, when forming multi-zone EPS models it should be reasonable to consider only the constraints having an impact on the possibility to utilize capacity margins in order to meet all power demands, in other words to identify the determinant levels of CA in different points of electric power system.

An analysis of worldwide studies of CA given in [5] shows that in spite of large-scale application of software packages for CAI assessment, there are no completely formalized approaches with regard to the formation of transport models in EPS. This is due, first, to the fact that in developed countries the studies of EPS CA are performed on a regular basis and the gained calculation and operation experience makes it possible to set margins of reliability zones without applying a formalized analysis of the structure and eventual operating states of EPS. Moreover, a rather simple structure of EPS allows defining in some cases the reliability zone margins at the expert level.

At the same time in UES of Russia the common practice describing the domains of admissible operational states for EPS has been developed on the basis of real power with the use of maximum allowed power flow (MAPF) values in controlled sections [7]. The formalized methods applied for the formation of EPS multi-zone models and CAI assessment with the use of MAPF values in controllable sections have been developed and presented in $[8,9]$. Let us consider the possibility to optimize the approaches proposed in cited papers with due account made for economic aspects of the choice of facilities ensuring CA.

\section{Cost-correlation of facilities ensuring CA}

As specified above, the influence of a given constraint on EPS CA levels is one of the criteria for transmission constraint satisfaction while forming a multi-zone transport model. On the other hand, as it was mentioned, the main objective of CAI calculation is to define the required level of generating capacity margin, i.e. its volume and location within EPS in order to ensure a required level of $\mathrm{CA}$. This being the case, when evaluating and accordingly when forming multi-zone transport models it should be useful to take into account the transmission constraints only for those power grid segments whose cost of transmission capacity increase correlates with that one of new generating capacity construction.

Major factors constraining the transmission capacity of power grid are as follows:

1. Continuous current carrying load of power equipment (under normal and post-fault operational conditions) which is, as a rule, a determinant transmission constraint for $220 \mathrm{kV}$ and above power grid;

2. Minimum accessible margin in terms of steadystate stability accord-ing to [10] (under normal and postfault operational conditions) which is, as a rule, a determinant factor for long-distance extra- and ultra-high voltage transmission lines.
Let us evaluate the cost of power grid transmission capacity growth as compared to that one of new generating capacity. To do that, data from [11] have been taken to estimate the cost of new generating capacity construction while data from [12] have been taken to evaluate the cost of engineering measures aimed at increasing the power grid transmission capacity (in average for territorial entities of the Russian Federation). Relevant data are given in Table 1.

Table 1. Cost of generating facility and measures providing the increase of power grid transmission capacity.

\begin{tabular}{|c|c|}
\hline Measures & $\begin{array}{c}\text { Cost, } \\
\text { mln. RUR }\end{array}$ \\
\hline $\begin{array}{c}\text { New generating facility, } \\
\text { per 1 MW of installed capacity }\end{array}$ & $\begin{array}{c}28,8-41,9 \\
\text { (fuel }- \text { gas) } \\
49,2-53,5 \\
\text { (fuel }- \text { coal) }\end{array}$ \\
\hline $\begin{array}{c}\text { Construction of single-circuit } \\
\text { overhead line, } \\
\text { per 1 km at rated voltage of: }\end{array}$ & \\
\hline $110 \mathrm{kV}$ & $7,9-8,7$ \\
\hline $220 \mathrm{kV}$ & $12,0-12,2$ \\
\hline $330 \mathrm{kV}$ & $12,8-13,4$ \\
\hline 500 kV & $18,2-20,1$ \\
\hline $\begin{array}{c}\text { Controlled shunt reactor, } \\
\text { per 3a } 1 \mathrm{MVAr}\end{array}$ & $2,0-4,1$ \\
\hline $\begin{array}{c}\text { Static capacitor bank, } \\
\text { per 1 MVAr }\end{array}$ & $0,3-0,6$ \\
\hline
\end{tabular}

The calculation of the cost of power grid transmission capacity has been performed on the basis of data given in Table 1 for $220 \mathrm{kV}$ and $500 \mathrm{kV}$ transmission lines. The results for $1 \mathrm{~kW}$ of transmission capacity against transmission route length are presented on Fig. 1. Charges due to the construction of overhead lines (wire type AC-500) and provision of substations with equipment (bank of transformers, breaker cells) of relevant voltage class have been taken into account.

The line transmission capacity was taken for calculations according to the following expression:

$$
P_{\max }=\min \left(P_{s} ; 0,8 \frac{U_{\text {nom }}^{2}}{x_{0} \ell}\right),
$$

where $P_{S}$ - maximum transmission capacity in terms of continuous current-carrying load accepted upon ata from [13] ( for $220 \mathrm{kV}-342 \mathrm{MW} \mathrm{OHL}$, for $500 \mathrm{kV}-1700$ MW OHL), $U_{n o m}-$ OHL rated voltage, $x_{0}-\mathrm{OHL}$ inductance per unit length, $\ell-$ OHL length. A critical OHL length (400 km and $1200 \mathrm{~km}$ for $220 \mathrm{kV}$ OHL and $500 \mathrm{kV}$ OHL respectively) has also been taken from [13].

On the basis of calculation data given on Fig. 1 one may state that for OHL of short or average length the cost of $1 \mathrm{~kW}$ of its transmission capacity will be considerably lower than that one of installed capacity of new generating facility and only in the case when it is 
close to its critical length (400 km for $220 \mathrm{kV}$ OHL and $800 \mathrm{~km}$ for $500 \mathrm{kV} \mathrm{OHL}$ ) the above costs may correlate. However, it should be noted that for $250-350 \mathrm{~km}$ long OHL there is a linear relationship between its cost and length. The transmission capacity of this OHL is limited by continuous current-carrying load and is independent of its length. The transmission capacity of long-distance OHL is specified by operating transmission limit in terms of steady-state stability which is, in its turn, inversely proportional to $\mathrm{OHL}$ inductance and accordingly to its length. In this context, the cost of 1 $\mathrm{kW}$ of transmission capacity of such an OHL is in quadratic dependence of its length.

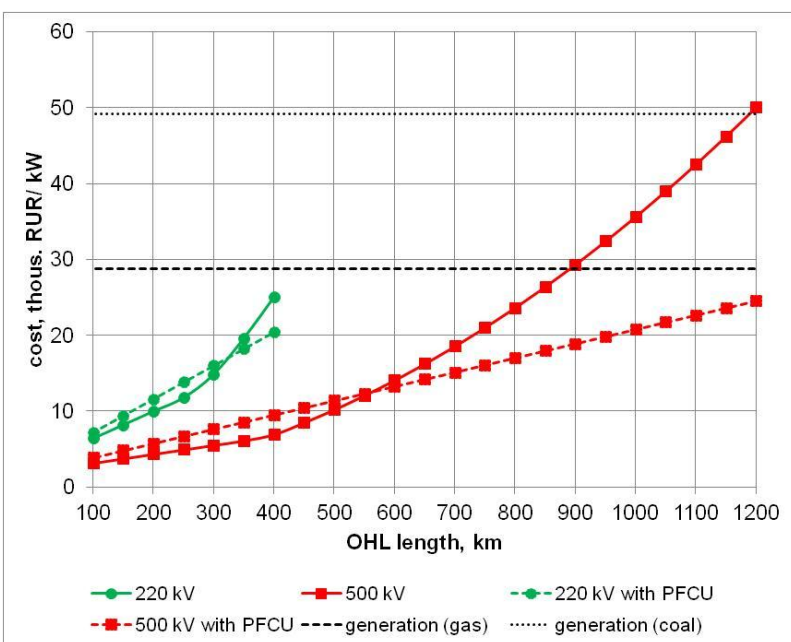

Fig. 1. Cost of $220 \mathrm{kV}$ and $500 \mathrm{kV}$ OHL transmission capacity.

In addition, the cost of OHL transmission capacity with due account made for power factor compensation has been considered. Figure 1 shows these relationships as dashed lines with relevant markers. The installation of power factor correction units (PFCU) [14] at intermediate substations requires additional expenses and results in OHL cost rise, but it allows regulating voltage levels and increasing OHL transmission capacity up to the value $P_{S}$. As it is shown on Fig. 1, this involves the reduction of $1 \mathrm{~kW}$ transmission capacity cost of long OHL as the effect due to the transmission capacity increase exceeds additional expenses connected with PFCU. Hence, the cost of $1 \mathrm{~kW}$ transmission capacity of long OHL is beyond that one of installed capacity of new generating facility even at OHL critical lengths.

The following expression has been applied to estimate a PFCU overall capacity in order to fully compensate the reactive power losses of OHL:

$$
Q_{P F C U}=\frac{P_{S}^{2}}{U_{\text {nom }}^{2}} x_{0} \ell .
$$

With reference to the foregoing, a general conclusion may be drawn, i.e. to eliminate a local power system deficiency it would be economically feasible to consider, first, the development of power grid, including the increase of transmission capacity of existing OHL by using PFCU and to build new power transmission capacities when required. Consequently, while estimating and forming multi-zone transport models of
EPS it would be useful to consider only transmission constraints for long OHL under conditions of full compensation of reactive power losses, because the increase of transmission capacity of these power grid segments correlates in cost with the construction of new generating capacities.

\section{Correlation between facilities ensuring $\mathrm{CA}$ in terms of their effect}

The conclusion made at the end of previous section does not consider the constraints available at selecting the OHL voltage class and respectively their transmission capacity.

It should be noted that if the cost of new generating facility is practically pro rately dependent on its installed capacity, the OHL cost is mostly determined by its voltage class. The choice of wire type and other equipment affecting the transmission capacity of OHL has a minimum effect on its overall cost. Meanwhile, the choice of voltage class for long OHL is limited by OHL critical length, which is specified, among other things, by losses due to capacity transmission [13].

In order to evaluate the effect of the above factor on the choice of facilities ensuring CA there has been carried out the correlation between alike in cost engineering measures aimed at increasing the installed generating capacity and the transmission capability of power grid on the basis of data given in Table 1 . Calculation results are shown on Fig. 2. The OHL length is laid off as abscissa while the installed power of new generating facility is laid off as ordinate. The curves exhibit the conformance between the installed power of new generating facility and the length of OHL alike in cost. Calculations have been performed for OHL with rated voltage of $220,380 \mathrm{kV}$ (wire type AC-300) and $500 \mathrm{kV}$ (wire type AC-400).

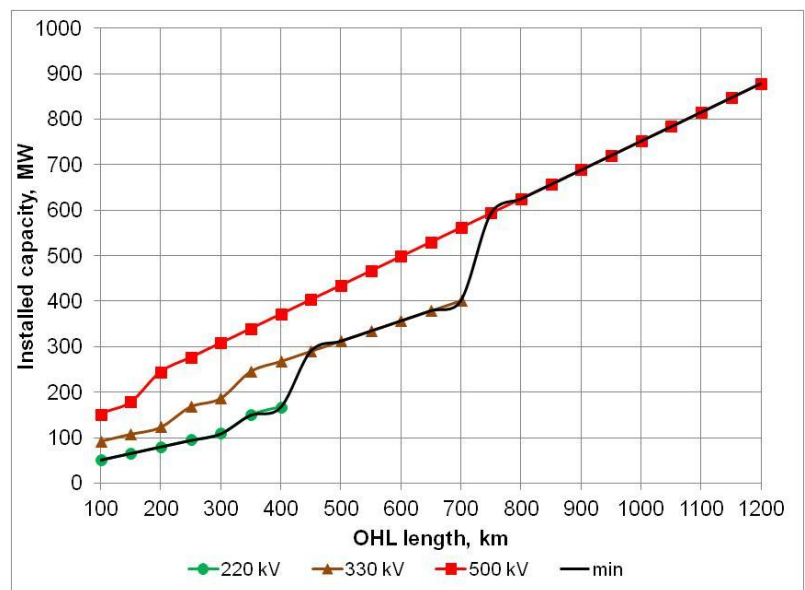

Fig. 2. Correlation between the installed capacity of new generating facility and the length of OHL alike in cost.

The curves on figure 2 are limited to the right by OHL critical length upon data of [13]. Thus, if at OHL length up to $400 \mathrm{~km}$, its minimal cost (voltage class 220 $\mathrm{kV}$ ) correlates with the cost of 100-150 MW of new generation, then in case of longer distance the construction of new OHL may be justified if the power 
need makes $300 \mathrm{MW}$ and more. If the required need is below a "minimum" curve shown on figure 2 , the construction of new OHL makes no economic sense and it should be reasonable to consider the construction of a new power-producing facility of required capacity.

In this context, when forming multi-zone transport models of EPS it is useful to take into account not only the distance between EPS nodes, but their potential need of margin capacity which may be estimated as being that one for concentrated power system [15]. As far as it concerns remote nodes in case of their small need in margin capacity, it should be reasonable to separate them as specific reliability areas because the increase of power grid transmission capacity towards these nodes may become more expensive as compared to the installation of additional generating facilities therein.

\section{Concluding remarks}

Based on performed calculations the following recommendations may be proposed to form EPS transport models in order to estimate CAI with account made for the cost of engineering measures ensuring CA:

1. When forming EPS transport models and performing further CAI calculations, one should take into account the transmission capacity of OHL with PFCU use allowing increasing the transmission capacity of power grid and adjusting the load of some its components, as the cost of PFCU is by an order of magnitude lower than that one of new generating facility or new OHL. The rated power capacity and places of PFCU installation may be specified on the basis of calculations of power system states.

2. It should be useful to integrate EPS nodes located within up to $400 \mathrm{~km}$ distance (critical length for $220 \mathrm{kV}$ $\mathrm{OHL}$ ) in one zone of reliability because the cost of transmission capacity growth per $1 \mathrm{~kW}$ is greatly lower than that one of new generating facility and the minimum cost of new OHL is comparable to that one of generating facility of average capacity (up to $150 \mathrm{MW}$ ).

3. It should be reasonable to integrate EPS nodes (group of nodes) located within $400-1000 \mathrm{~km}$ in one area of reliability only when their potential need in margin capacity makes more than 300-750 MW (with respect to distance). Otherwise, it makes no sense to consider the construction of new OHL and the transmission constraints between these nodes (groups of nodes) should be considered when estimating CAI.

4. The EPS nodes (groups of nodes) within more than $1000 \mathrm{~km}$ are considered as individual reliability areas because the cost of new OHL construction over such distances is comparable to that one of new generating facility of relevant capacity.

\section{References}

1. R. Billinton, D. Huang, Canadian Conference on Electrical and Computer Engineering, 611 (IEEE, 2005)
2. N.A. Manov, Yu.Ya. Chukreev, N.V. Bobyliova, L.P. Solovieva, Proc. of the RAS. Energ. E 5, 74 (2009)

3. D.S. Krupenev, L.M. Lebedeva, G.F.Kovalev, N.A. Belyaev, A.Ye. Yegorov, Pv.E. Gromov, Energy policy,E 1, 33 (2018)

4. W. Li, Risk Assessment of Power Systems: Models, Methods and Applications (IEEE Press, New Jork, 2005)

5. Yu.Ya. Chukreev, M.Yu.Chukreev, Models of evaluation of capacity adequacy indices when managing the development of electric power systems (Komi scientific centre, Syktyvkar, 2014)

6. G.F.Kovaliov, L.M.Lebedeva; N.I.Voropay, Reliability of electric power systems (Nauka, Novossibirsk, 2015)

7. Yu.M. Sharguin, A.L. Koviazin, Ye.Ye. Popov, L.S. Smirnova, Proc. of HVDC Power Transmission Research Institute, E 65, 66 (2011)

8. N.A. Belyaev, A.Ye. Yegorov, N.V.Korovkin, V.S.Chudny, Power plants, E 11, 47 (2015)

9. N.A. Belyaev, N.V. Korovkin, V.S. Chudny, Electricity, E 5, 11 (2018)

10. Methodical provisions with regard to power system stability. Approved by the Order of the Ministry of Energy of Russia dated June 30, 2003, No. 277

11. Regulations concerning power pricing sold upon capacity supply agreements. Approved by the Decision of the Government of the Russian Federation dated April 13, 2010, No. 238

12. Aggregate standards of pricing typical process solutions for major construction works of electricity generation facilities with regard to power supply facilities. Approved by the Order of the Ministry of Energy of Russia dated February 8, 2016, No. 75

13. D.L.Faibisovitch, Handbook for power grids designing (NC ENAS, Moskow, 2012)

14. N.G. Hingorani, L. Gyugyi, Understanding FACTS. Concepts and Technology of Flexible AC Transmission Systems (IEEE press, New Jork, 2006)

15. I.M. Markovitch, Power system states (Energy, Moskow, 1969) 